\title{
Electroless Ni-P Deposition through Imperfections in Anodic Oxide Films on Aluminum and Al5052 Alloy
}

\author{
Sungmo MoON, Masatoshi SAKAIRI, Hideaki TAKAHASHI, and Kiyotaka SHIMAMURA*
}

\author{
Department of Molecular Chemistry, Graduate School of Engineering, Hokkaido University (Sapporo 060-8628, Japan) \\ * Sapporo Electro Plating Industry Co., LTD (Hassamu 13-jo 12-Choume 2-15, Nish-Ku, Sapporo 063-0833, Japan)
}

Received September 17, 2002 ; Accepted January 28, 2003

\begin{abstract}
The present investigation examined how to prevent Ni-P deposition through imperfections in anodic oxide films on aluminum and Al5052 alloy during electroless-plating. Pure aluminum and Al5052 alloy specimens were anodized in a sulfuric acid solution to form porous oxide films, and then immersed in boiling water to seal the pores. Confocal scanning laser microscopy was applied to examine the effect of pore-sealing on the Ni-P electroless deposition through imperfections. There were Ni-P domes deposited on both pure aluminum and Al5052 alloy covered with anodic oxide films through the imperfections in the oxide film. The number of Ni-P domes increased with electroless plating time on both kinds of specimens, and this change was more remarkable on Al5052 alloy, due to imperfections originating from second phase particles in the alloy substrate. Sealing treatment effectively prevented Ni-P dome deposition on both types of specimens, due to healing of the imperfections in the oxide films. Longer anodizing before the sealing treatment prevented the Ni-P deposition completely on the Al5052 alloy specimen even after $15 \mathrm{~h}$ of electroless plating.
\end{abstract}

Key Words : Aluminum, Al 5052 Alloy, Anodic Oxide Film, Ni-P Electroless Deposition, Confocal Laser Microscopy

\section{Introduction}

Local electroless metal deposition is widely used in the fabrication of microelectronic devices, printed circuit boards, and in local modification of aluminum surfaces. ${ }^{1-5}$ Chu et al.$^{2-4}$ employed electroless Ni-P plating and laser irradiation techniques for patterning of aluminum surfaces with sealed porous type anodic oxide films to prevent the electroless deposition of Ni-P and they introduced a laser irradiation technique to remove the anodic oxide film locally. Electroless deposition of $\mathrm{Ni}$ $\mathrm{P}$ occurred preferentially at the laser-irradiated areas and no deposition of $\mathrm{Ni}-\mathrm{P}$ was observed on the non-laserirradiated oxide surface after $1 \mathrm{~h}$ of electroless plating time. ${ }^{2-4)}$

The authors attempted to apply the laser irradiation / electroless plating technique in the fabrication of a plastic injection mold. ${ }^{6}$ In the fabrication of the mold, $\mathrm{Al}$ 5052 alloy was used as mold material because of its good mechanical properties and high formation rates of anodic oxide film. ${ }^{4.6)}$ In the process, a relatively thick $\mathrm{Ni}-\mathrm{P}$ layer is necessary to ensure an anti-wear surface. Electroless plating for long periods, however, may cause the nucleation of Ni-P particles through imperfections in the anodic oxide film on pure aluminum and $\mathrm{Al}$ alloys. The tendency may be more remarkable on Al5052 alloy since more imperfections could be included in anodic oxide films, due to the preferential dissolution of alloying elements or the incorporation into the oxide film. The formation of imperfections in anodic oxide films during anodizing of A15052 alloy has been investigated by confocal scanning laser microscopy (CSLM) elsewhere. ${ }^{7}$

In the present investigation, the effects of the imper- fections on the electroless deposition of Ni-P were examined during a relatively long period of electroless plating on pure aluminum and A15052 alloy by CSLM.

\section{Experimental}

\section{1 Specimens and pretreatments}

Two kinds of materials were used as specimens: 99.99 purity aluminum sheet and $\mathrm{Al} 5052-\mathrm{H} 32$ alloy sheet $(\mathrm{Cu}$ : 0.02, Si:0.07, Fe:0.25, Mn:0.01, Mg:2.66, Zn:<0.01, Cr: 0.19, Ti:0.02, and Al:bal.). The specimens were cut from the sheets and then partly sealed with epoxy resin, leaving an exposed area of $1 \mathrm{~cm}^{2}$, followed by ultrasonic wave cleaning in ethyl alcohol. The specimens were electropolished for $2 \mathrm{~min}$ in a mixture of acetic acid and 70 $\%$ perchloric acid $(4: 1)$ at $284 \pm 1 \mathrm{~K}$.

\section{2 Anodizing and sealing}

The pretreated specimens were anodized in $16 \mathrm{wt} \%$ $\mathrm{H}_{2} \mathrm{SO}_{4}$ solution at $20 \mathrm{~V}$ and $274 \pm 0.5 \mathrm{~K}$ for $\mathrm{t}_{\mathrm{a}}=0.5-2 \mathrm{~h}$ to obtain hard, porous anodic films with different thicknesses. An anodizing voltage of $20 \mathrm{~V}$ was applied between the working electrode and platinum foil counter electrode by a GP035-10 Regulated DC Power Supply (Takasago, LTD). Some anodized specimens were immersed in boiling pure water for $t_{\mathrm{s}}=30 \mathrm{~min}$ to seal the pores of the anodic oxide films.

\section{3 Electroless plating}

The unsealed and sealed anodic oxide film-covered specimens were immersed for $t_{p}=10$ min- $15 \mathrm{~h}$ in a mixture of commercial electroless Ni-P plating solutions of Melplate Ni-875A and Melplate Ni-875B (Meltex INC., $\mathrm{pH}=5.0$ ) at $363 \pm 1 \mathrm{~K}$. The solution was circulated to agitate the solution and to keep the concentration constant 
during elctroless plating.

\section{4 Observation}

The surface and vertical section of specimens after $\mathrm{Ni}$ $\mathrm{P}$ electroless plating were observed with a confocal scanning laser microscope (CSLM, Laser-Tec Co.). To observe vertical sections of anodic oxide films, sectioning of anodized specimens was performed with a diamond knife using a Leica ultramicrotome after embedding in an epoxy resin block. The surface of the remaining block after the sectioning was observed under CSLM. The preparation procedure of the block specimen using the ultramicrotome has been detailed elsewhere. ${ }^{8)}$ The crosssection of the Ni-P plated specimen was prepared by cutting and abrading with SiC emery papers up to \#1500.

\section{Results}

\section{1 i $\mathbf{i}_{\mathrm{a}}$-t curves}

Figure 1 shows the time variations in anodic current on pure aluminum and Al5052 alloy during anodizing in $16 \mathrm{wt} \%$ sulfuric acid at $20 \mathrm{~V}$ and $283 \mathrm{~K}$. After an initial transient, the current reaches steady values of $60 \mathrm{~A} \mathrm{~m}^{-2}$ on pure aluminum and $72 \mathrm{~A} \mathrm{~m}^{-2}$ on Al5052 alloy. The higher steady value on the alloy suggests easier transport of ions through the barrier layer of anodic oxide films formed on the alloy. ${ }^{5}$ ) The steady values on pure aluminum and Al5052 alloy remained unchanged for $2 \mathrm{~h}$.

\section{2 CSLM images of the anodic oxide films}

Figure 2 shows CSLM contrast images of crosssections of anodic oxide films formed on pure aluminum and Al5052 alloy for $t_{a}=30 \mathrm{~min}$. The section of anodic oxide film on pure aluminum shows a relatively uniform thickness of about $6.9 \pm 0.1 \mu \mathrm{m}$ with no visible imperfections in the $\mu \mathrm{m}$ scale. On the other hand, a number of bright (white arrow) and dark (black arrow) circular regions, with sizes around $1 \mu \mathrm{m}$, appear in the anodic oxide film formed on the Al5052 alloy, and the thickness of the film appears to be about $7.4 \pm 0.4 \mu \mathrm{m}$. The thicker anodic oxide film on the Al5052 alloy is due to the higher steady current on the alloy (see Fig. 1).

The bright and dark regions in the anodic oxide film formed on Al5051 alloy appear to arise from secondphase particles in the Al5052 alloy, which contain mainly

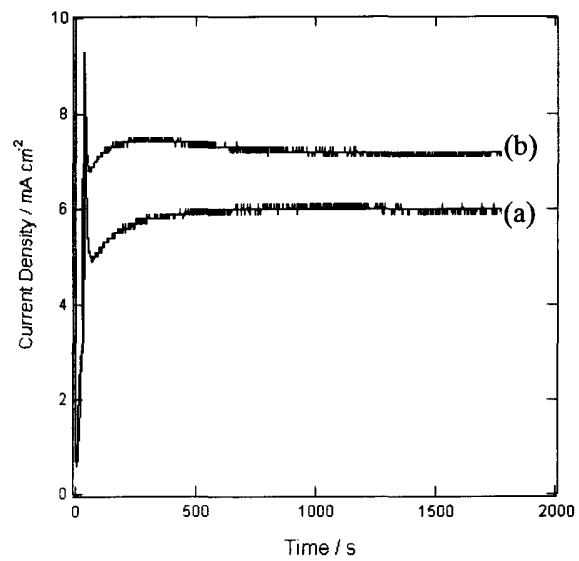

Fig. 1 Anodic current density of (a) pure aluminum and (b) Al5052 alloy during anodizing in $16 \mathrm{wt} \%$ sulfuric acid solution at $20 \mathrm{~V}$ and $274 \pm 0.5 \mathrm{~K}$.
$\mathrm{Al}-\mathrm{Mg}$ and Al-Fe-Mg metallic compounds. The bright regions are imperfections containing Fe-rich oxide, and dark regions are voids formed by a preferential dissolution of Al-Mg intermetallic compounds. ${ }^{7)}$ The preferential dissolution of $\mathrm{Mg}$ may lead to the higher value of the steady current in Fig. 1.

Figure 3 shows CSLM contrast images of the surface of (a) pure $\mathrm{Al}$ and (b) Al5052 alloy before and after anodizing for $t_{a}=30 \mathrm{~min}$. The surface of the pure aluminum appears to be relatively smooth without visible imperfections before or after anodizing. The surface of the Al5052 alloy, however, shows a number of imperfections arising from second-phase particles both before and after anodizing. The size and number of imperfections after anodizing are much larger than before anodizing, and this can
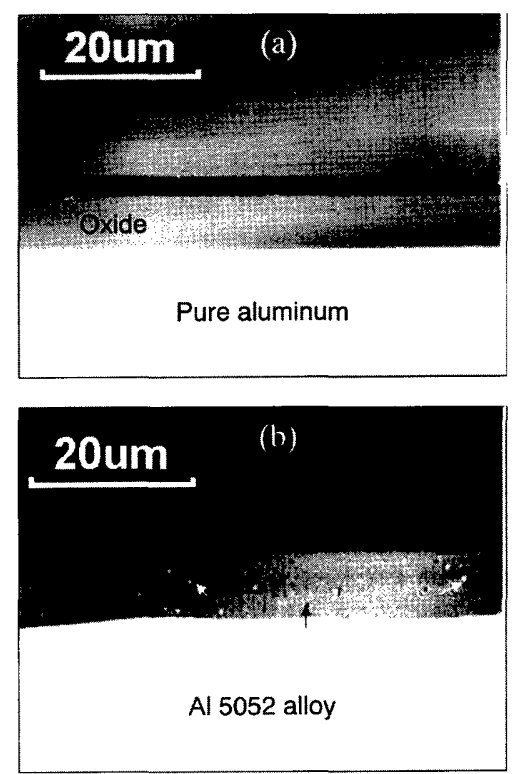

Fig. 2 CSLM contrast images of cross-sections of (a) pure aluminum and (b) Al5052 alloy anodized for $30 \mathrm{~min}$ in $16 \mathrm{wt}$ $\%$ sulfuric acid solution at $20 \mathrm{~V}$ and $274 \pm 0.5 \mathrm{~K}$. The crosssections were prepared by sectioning with a diamond knife using ultramicrotome.

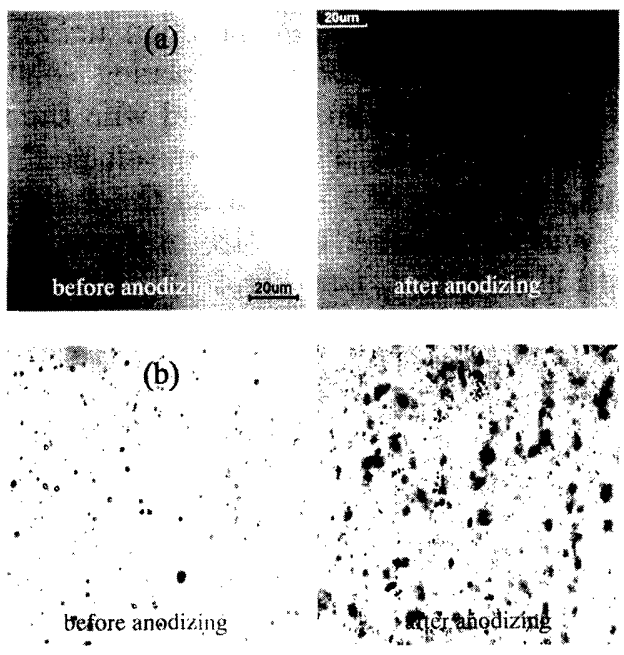

Fig. 3 CSLM contrast images of (a) pure aluminum and (b) Al5052 alloy obtained before and after anodizing for $30 \mathrm{~min}$ in $16 \mathrm{wt} \%$ sulfuric acid solution at $20 \mathrm{~V}$ and $274 \pm 0.5 \mathrm{~K}$. 


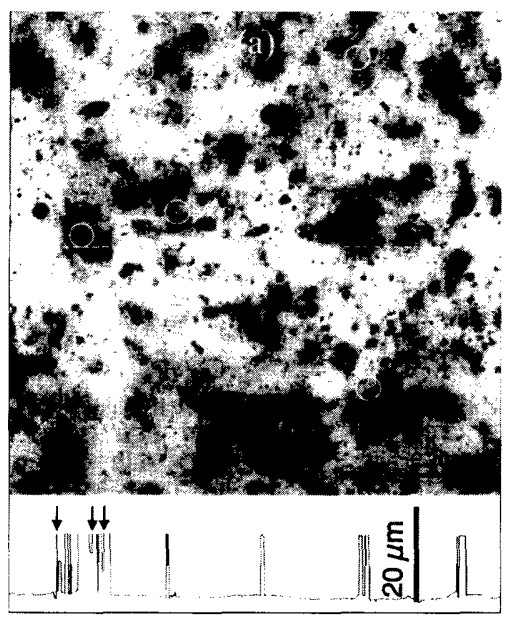

Fig. 4 Typical CSLM contrast image of Al5052 alloy and cross-sectional profile across the dashed line, obtained after anodizing for $2 \mathrm{~h}$ in $16 \mathrm{wt} \%$ sulfuric acid solution at $20 \mathrm{~V}$ and $274 \pm 0.5 \mathrm{~K}$.

be explained by the formation and overlapping of imperfections during anodizing. ${ }^{7)}$

The imperfections in the anodic oxide film on the $\mathrm{Al}$ 5052 alloy can also be seen from the top view CSLM image. Figure 4 shows a typical CSLM contrast image of the top view of Al5052 alloy anodized for $t_{a}=2 \mathrm{~h}$ and $\mathrm{a}$ cross-sectional profile across the dashed line in the CSLM image. Two different types of defects are clearly observed : small bright spots in white circles and larger dark regions. The cross-sectional profile shows that the bright regions are present in the middle of the anodic oxide film, as indicated by arrows.

3. 3 Electroless deposition of Ni-P on the anodic oxide film-covered aluminum

After anodizing for $t_{a}=30$ min, pure aluminum and $\mathrm{Al}$ 5052 alloy specimens which were not subjected to poresealing, were immersed in Ni-P electroless plating solution for (a) $\mathrm{t}_{\mathrm{p}}=10 \mathrm{~min}$, (b) $30 \mathrm{~min}$, and (c) $60 \mathrm{~min}$, and CSLM contrast images of the Ni-P plated specimen surface are given in Fig. 5. After $t_{p}=10 \mathrm{~min}$, the unsealed anodic oxide film-covered pure $\mathrm{Al}$ specimen shows a network pattern along the rolling direction unlike that before immersing in Ni-P electroless plating solution (see Fig. 3). The pure $\mathrm{Al}$ specimen covered with the unsealed anodic oxide film shows a few "dome-shaped" Ni-P deposits with a diameter of $1-3 \mu \mathrm{m}$ on the surface after $t_{p}$ $=30 \mathrm{~min}$, and the number and size of these deposits increase with increasing $t_{p}$ (see Fig. 5-a).

The surface of unsealed anodic oxide film-covered $\mathrm{Al}$ 5052 alloy specimens shows a number of Ni-P domes even after $t_{p}=10$ min, and all the Ni-P domes coalesce to cover all of the surface after $t_{p}=60$ min (Fig. 5-b). It must be noted that the Ni-P domes on the unsealed anodic oxide film-covered pure aluminum surface are relatively uniform in size, while there is a variety of sizes on the unsealed anodic oxide film-covered Al5052 alloy surface.

The sealing treatment of the anodic oxide film may prevent the nucleation of Ni-P on the anodic film-covered aluminum surface. Figure 6 shows a complete prevention
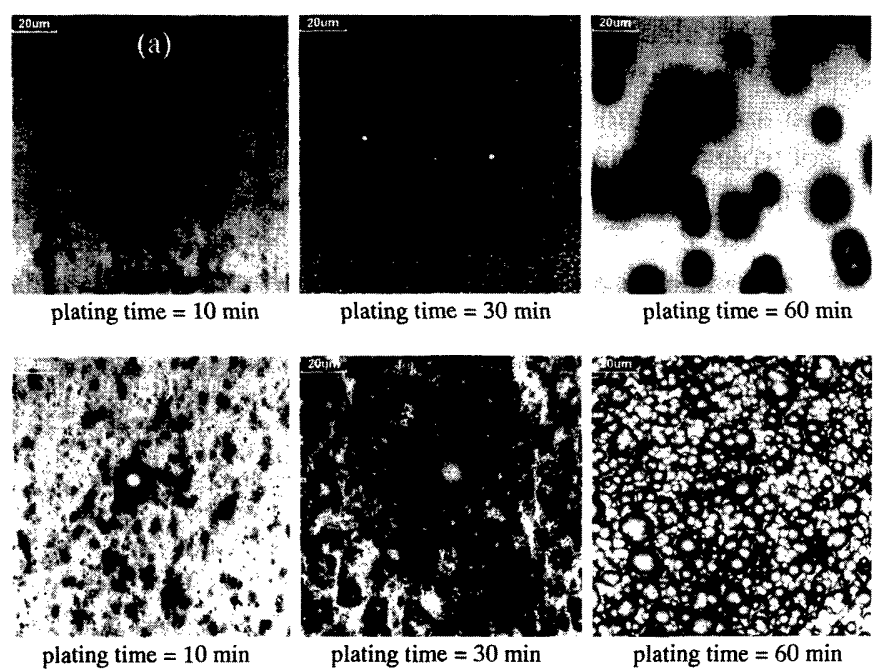

Fig. 5 CSLM contrast images of (a) pure aluminum and (b) Al5052 alloy, previously anodized for $30 \mathrm{~min}$, with Ni-P plating time in a mixture of electroless Ni-P plating solutions of Melplate Ni-875A and Melplate Ni-875B (Meltex INC.) at 363 $\pm 1 \mathrm{~K}$.
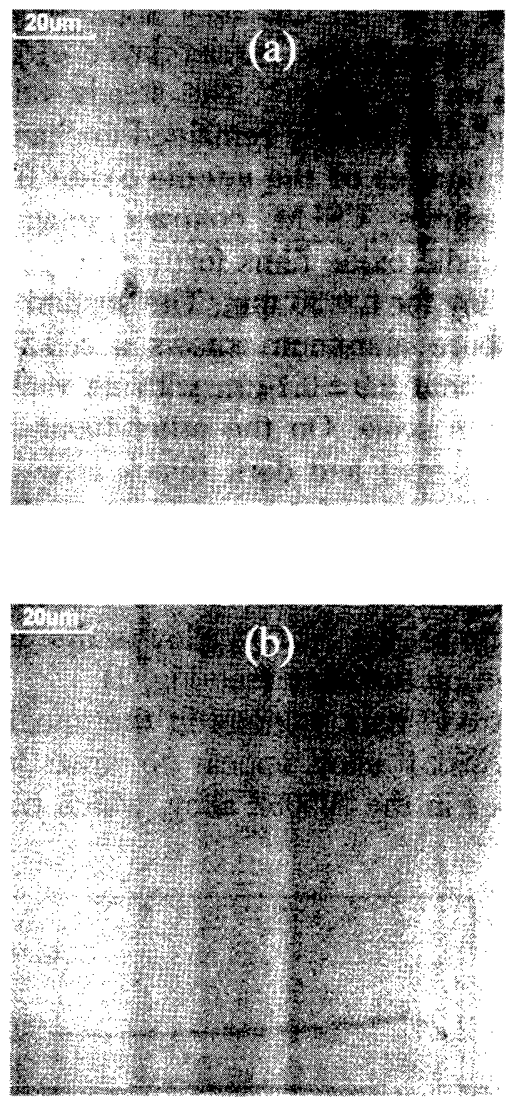

Fig. 6 CSLM contrast images of pure aluminum, previously anodized for $30 \mathrm{~min}$ and then sealed for $30 \mathrm{~min}$ in boiling water, with Ni-P plating time of (a) $5 \mathrm{~h}$ and (b) $10 \mathrm{~h}$.

of Ni-P nucleation by $t_{s}=30$ min sealing treatment for a $t_{a}$ $=30$ min anodic oxide film covered-pure aluminum after $\mathrm{t}_{\mathrm{p}}=10 \mathrm{~h}$ of electroless plating time.

Different from this, the sealing treatment of the anodic oxide film on Al5052 alloy does not completely prevent the nucleation of Ni-P on the alloy although the number of Ni-P domes is significantly reduced, as seen in Fig. 7 . 

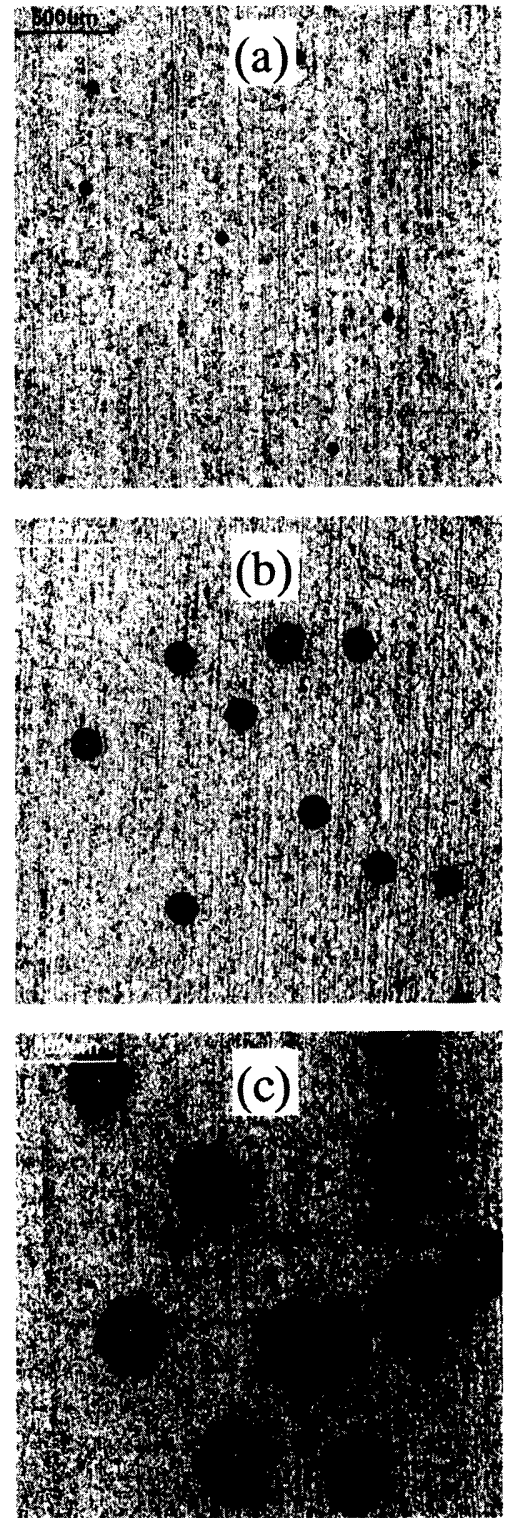

Fig. 7 CSLM contrast images of A15052 alloy, previously anodized for $30 \mathrm{~min}$ and then sealed for $30 \mathrm{~min}$ in boiling water, with Ni-P plating time of (a) $3 \mathrm{~h}$, (b) $7 \mathrm{~h}$, and (c) $15 \mathrm{~h}$.

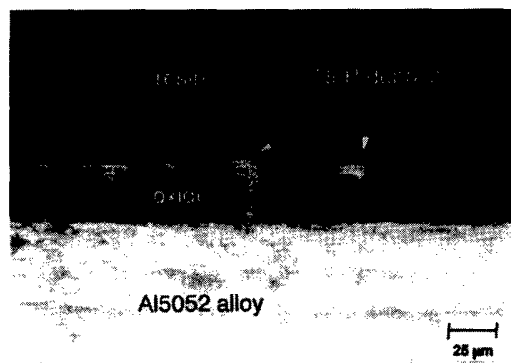

Fig. 8 Optical micrograph of cross-section of Al5052 alloy anodized for $1.5 \mathrm{~h}$, sealed for $30 \mathrm{~min}$ and then immersed for $7 \mathrm{~h}$ in a mixture of electroless Ni-P plating solutions of Melplate Ni-875A and Melplate Ni-875B (Meltex INC.) at 363 $\pm 1 \mathrm{~K}$. The cross-section was prepared by abrading with $\mathrm{SiC}$ emery paper.

This suggests that there are sites in the sealed anodic oxide film on Al5052 alloy where the nucleation of Ni-P particles is possible. The lower number of deposited Ni-P
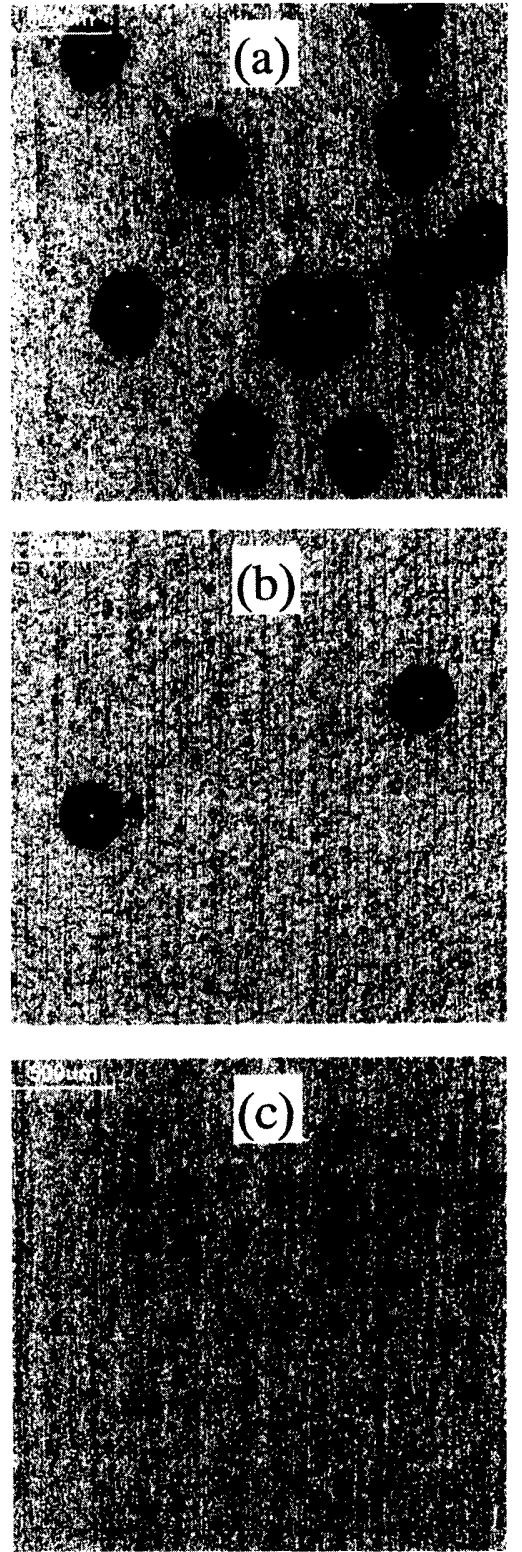

Fig. 9 CSLM contrast images of Al5052 alloy immersed for $15 \mathrm{~h}$ in a mixture of electroless Ni-P plating solutions of Melplate Ni-875A and Melplate Ni-875B (Meltex INC.) at 363 $\pm 1 \mathrm{~K}$, with previous anodizing time of : (a) $0.5 \mathrm{~h}$, (b) $1 \mathrm{~h}$, and (c) $2 \mathrm{~h}$. The specimens were sealed for $30 \mathrm{~min}$ in boiling water after the anodizing and then used for the electroless Ni-P plating.

particles suggests that most imperfections in the anodic oxide film become inactive or are healed by the sealing treatment but that some of the imperfections remain active even after the sealing treatment.

The nucleation sites of Ni-P particles in the sealed anodic oxide film can be seen in optical micrographs of the cross-section obtained after $t_{p}=7 \mathrm{hr}$ Ni-P electroless plating, as shown in Fig. 8. Some Ni-P domes are connected to the alloy substrate with a Ni-P channel in the oxide film, while some of the Ni-P domes appear to be isolated from the alloy substrate. This suggests that Ni-P domes can be nucleated on the metal substrate and also in anodic oxide films.

Figure 9 depicts the effect of the anodic oxide film 
thickness on the prevention of electroless Ni-P deposition on Al5052 alloy. The number of Ni-P deposits was drastically reduced by the formation of a thicker anodic oxide film on Al5052 alloy, and this can be explained by a lowered probability of electron transfer between electroless $\mathrm{Ni}-\mathrm{P}$ plating solution and nucleation sites of Ni-P with increasing oxide film thickness. It is noticed that the anodic oxide film thickness of about $30 \mu \mathrm{m}$ obtained by anodizing for $2 \mathrm{~h}$, is sufficient to prevent the nucleation of Ni-P on Al5052 up to $15 \mathrm{~h}$ of plating time.

\section{Discussion}

4. 1 Type of imperfections in anodic oxide films and their effects on the electroless deposition of Ni-P

There are two kinds of imperfections in porous type anodic oxide films on pure aluminum and on $\mathrm{Al} 5052$ (Fig. 10). The first is fine cracks in the barrier layer, which are formed during anodizing due to chemical and physical inhomogeities at the region near the specimen surface, such as stress, roughness, inclusions and so on (Fig. 10-a). The imperfections in anodic oxide films on pure $\mathrm{Al}$ correspond mainly to these fine cracks. The $\mathrm{Al}$ 5052 alloy specimen includes many second phase particles, such as $\mathrm{Al}-\mathrm{Mg}$ and $\mathrm{Al}-\mathrm{Fe}-\mathrm{Mg}$ intermetallic compounds, and these particles cause different kinds of imperfections to form in the anodic oxide films (Fig. 10b). ${ }^{7}$ The $\mathrm{Al}-\mathrm{Mg}$ intermetallic compounds form voids in the oxide film by preferential dissolution of $\mathrm{Mg}$, and $\mathrm{Al}-$ $\mathrm{Fe}-\mathrm{Mg}$ particles form Fe-rich oxide films locally.

When unsealed anodic oxide film-covered specimens are immersed in the Ni-P electroless plating solution, the solution penetrates into the pores and imperfections to reach the interface between the oxide film and the metal substrate. The solution may dissolve the oxide slowly at a relative high temperature and in a weak acidic medium to widen the path-way diameter where solution penetrates during immersion. The network structure observed for unsealed anodic oxide film covered-pure $\mathrm{Al}$ specimens after $t_{p}=10$ min (Fig. 5 -a) can be explained as a result of the penetration of solution into the oxide / metal interface through these path-ways.

The aluminum substrate and the metallic compounds exposed to the solution at the interface may act as catalytic centers for Ni-P deposition during electroless plating. The Ni-P is deposited continuously on the nuclei through pores and imperfections in the anodic oxide film, and after filling these the deposition occurs on the oxide film surface to form dome-shaped deposits (Fig. 10-a).

There are many more imperfections in anodic oxide films formed on Al5052 specimens than on pure aluminum, and the size and shape vary widely (Fig. 10-c). This may lead to the formation of numerous, different sized nuclei of Ni-P deposits after $t_{p}=10 \mathrm{~min}$ on the unsealed anodic oxide film-covered Al5052 specimens (see Fig. 5b).

There are Al-Fe-Me intermetallic compounds in Al5052 alloy forming imperfections that contain Fe-rich oxide in the anodic oxide film (see Fig. 4), and these imperfections may cause nucleation of Ni-P particles in the anodic oxide film, as shown in Fig. 8. Metallic iron is possibly a) Pure Al, No-sealing

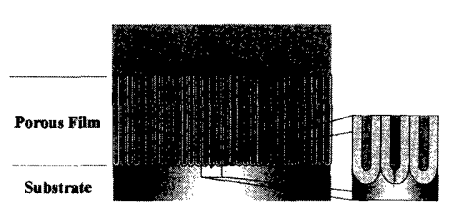

b) Pure Al, Sealing

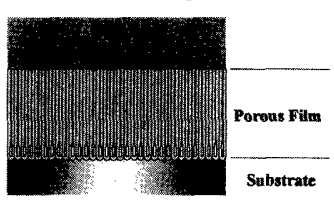

c) 5052 Alloy, No-sealing

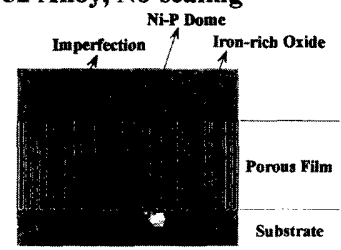

d) 5052 Alloy, Sealing

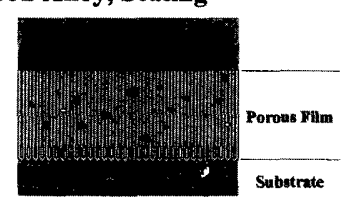

e) 5052 Alloy,

Long anodizing \& Sealing

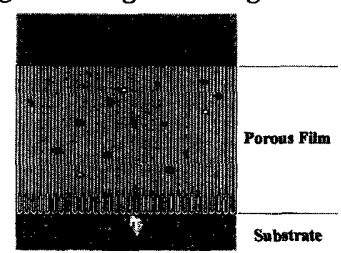

Fig. 10 Schematic model of the deposition of Ni-P domes through imperfections in anodic oxide films on pure aluminum ((a) and (b)) and Al5052 alloy ((c), (d), and (e)), and the inhibition of Ni-P deposition by sealing.

included in these imperfections playing a roll as catalysts in the nucleation.

\section{2 Avoiding of the effects of defects}

The contribution of micro cracks in the barrier layer and pores in the porous layer to the nucleation of Ni-P becomes negligible by the sealing treatment of the anodic oxide film in boiling water, as manifested by an absence of deposition of Ni-P on the sealed anodic oxide film-covered pure aluminum (Fig. 6). During sealing treatment in boiling water, anodic oxide films react with water to form hydroxide. ${ }^{9 !}$

$$
\mathrm{Al}_{2} \mathrm{O}_{3}+(1.8-2.0) \mathrm{H}_{2} \mathrm{O}=\mathrm{Al}_{2} \mathrm{O}_{3} \cdot(1.8-2.0) \mathrm{H}_{2} \mathrm{O}
$$

Conversion of anhydrous oxides with a density of $\rho=3.0$ $\mathrm{g} \mathrm{cm}^{-3}$ to hydroxides with $\rho=2.4 \mathrm{~g} \mathrm{~cm}^{-3}$ leads to sealing of pores by a volume expansion. ${ }^{9)}$ Pore sealing in region near the pore bottom may proceed more slowly because of a slower supply of $\mathrm{H}_{2} \mathrm{O}$. The pore sealing prevents Ni-P deposition through micro cracks on the sealed anodic oxide film-covered pure aluminum (Fig. 10-b).

The voids and Fe-rich oxide imperfections in the oxide film formed on Al5052 alloy, however, are not healed completely by the sealing treatment, because the sizes, about $1 \mu \mathrm{m} \phi$ are larger than that of the micro cracks in the oxide film formed on pure aluminum. However, these cracks may be isolated from the surface and the metal substrate by sealing of the connecting pores during the sealing treatment (Fig. 10-d). Thicker anodic oxide films make the isolation of imperfections more complete, leading to the experimental result that no deposition of Ni-P occurs even after $15 \mathrm{~h}$ of electroless plating on Al5052 alloy specimen covered with $30 \mu \mathrm{m}$ sealed anodic oxide 
films (Fig. 10-e).

In summary, the formation of thicker oxide films and pore sealing are effective to prevent Ni-P deposition through imperfections. These treatments may be applied for the prevention of Ni-P deposition on other types of aluminum alloys by selecting adequate anodizing times.

\section{Conclusions}

1. The electroless deposition of Ni-P domes occurs on the unsealed anodic oxide film-covered pure aluminum through cracks in the porous and barrier layer of the oxide. The deposition of Ni-P on pure aluminum can be prevented completely by sealing of the anodic oxide film.

2. There are two kinds of imperfections in the anodic oxide film formed on Al5052, Fe rich oxide imperfections and voids, and both make the deposition of $\mathrm{Ni}-\mathrm{P}$ on $\mathrm{Al}$ 5052 alloy much easier than on pure aluminum. Complete prevention of Ni-P dome formation on $\mathrm{Al} 5052$ specimens is possible by covering the alloy with more than 30 $\mu \mathrm{m}$-thick anodic oxide film and by sealing the pores sufficiently.

\section{Acknowledgements}

This work was supported by the Light Metal Foundation of Japan, Hokkaido foundation for the Promotion of Science and Technology, a Grant-in-Aid of JSPS (Japan
Society for the Promotion of Science) and Creative and Fundamental R\&D Program of Japan Small Business Corporation. One of the authors (S.M.M.) is indebted to JSPS for financial support during a postdoctoral fellowship at the Interface and Micro-Structure Analysis Laboratory of Hokkaido University.

\section{Referenses}

1) S. Zhang, J. De Baets, M. Vereeken, A. Vervaet, and Van Calster, J. Electrochem. Soc., 146, 2870 (1999).

2) S, Z, Chu, M. Sakairi, H. Takahashi, and Z. X. Qiu, J. Electrochem. Soc., 146, 537 (1999).

3) S, Z, Chu, M. Sakairi, I. Saeki, and H. Takahashi, J. Electrochem. Soc., 146, 2876 (1999).

4) S, Z, Chu, M. Sakairi, and H. Takahashi, J. Electrochem. Soc., 147, $1423(2000)$.

5) S, Z, Chu, M. Sakairi, H. Takahashi, K. Simamura, and Y. Abe, J. Electrochem. Soc., 147, 2181 (2000).

6) M. Sakakiri, S.-M. Moon, H. Takahashi, and K. Shimamura, J. Surface Finishing Soc., 52, 553 (2001)

7) S.-M. Moon, M. Sakairi, and H. Takahashi, submitted to J. Electrochem. Soc.

8) F. Echeverria, P. Skeldon, G. E. Thompson, H. Habazaki and K. Shimizu, J. Electrochem. Soc., 146, 3711(1999).

9) M. Koda, H. Takahashi, and M. Nagayama, J. Metal Finishing Soc. Jpn., 33, 242 (1982). 